\title{
Event-duration discrimination by pigeons: The choose-short effect may result from retention-test novelty
}

\author{
BRIGETTE R. DORRANCE, DAREN H. KAISER, and THOMAS R. ZENTALL \\ University of Kentucky, Lexington, Kentucky
}

\begin{abstract}
Pigeons trained on a conditional event-duration discrimination typically "choose short" when retention intervals are inserted between samples and comparisons. In two experiments, we tested the hypothesis that this effect results from ambiguity produced by the similarity of the novel retention intervals and the familiar intertrial interval by training pigeons with retention intervals from the outset and, for one group, in addition, making retention intervals distinctive from the intertrial intervals. In Experiment 1 , when the retention intervals $(0-4 \mathrm{sec})$ were not distinctive from the intertrial intervals, the pigeons did not show a clear choose-short effect even when extended retention intervals ( $8 \mathrm{sec}$ ) were introduced. When the retention intervals were distinctive, the pigeons showed a choose-long effect (they appeared to time through the retention interval), but it was relatively weak until the retention intervals were extended to $8 \mathrm{sec}$. In Experiment 2, when pigeons were discouraged from timing through the retention intervals by making the intertrial intervals and retention intervals salient distinct events and using long (up to 16 -sec) retention intervals in training, parallel retention functions were found. It appears that when ambiguity is removed, forgetting by pigeons does not occur by the process of subjective shortening. These experiments suggest that the accurate interpretation of results of animal memory research using differential-duration samples must consider the novelty of the retention intervals on test trials as well as their similarity to other trial events.
\end{abstract}

When pigeons are trained on a conditional discrimination in which the duration of the sample serves as the conditional stimulus (a short sample indicates that one of the comparisons is correct, and a long sample indicates that the other comparison is correct), the slope of the retention function with increasing delays depends on whether the sample is the longer or the shorter duration. Specifically, as retention intervals increase, matching accuracy on the short-sample trials typically remains high, but matching accuracy on the long-sample trials declines rapidly - often falling below chance at longer retention intervals (e.g., Spetch \& Wilkie, 1982). These results have been interpreted as evidence of the subjective shortening of event duration with increasing retention intervals. That is, as the retention interval increases, memory for the sample duration shortens, such that, after longer retention intervals, memory for the long sample is actually more similar to that of the short sample at no delay (see Staddon \& Higa, 1999 , for a formal version of this model).

Surprisingly, however, there is evidence, that this "choose-short" effect can be eliminated by merely illuminating the houselight during the intertrial interval. Under these conditions, the pigeons show parallel reten-

This research was supported by National Science Foundation Grant IBN 941489 and National Institute of Mental Health Grants 55118 and 59194. Correspondence should be addressed to T. R. Zentall, Department of Psychology, University of Kentucky, Lexington, KY 405060044 (e-mail: zentall@pop.uky.edu). tion functions (Spetch \& Rusak, 1992). To account for this finding, Spetch and Rusak proposed that the pigeons evaluate the durations of the samples relative to the temporal context in which they occur-that is, relative to both the preceding event (the intertrial interval) and the following event (the retention interval), which collectively comprise the temporal background against which the sample is judged. Furthermore, according to the relative duration hypothesis, for the relation between the sample and the temporal background to control the pigeons' choice, the intertrial-interval and the retention-interval stimulus conditions must provide a relatively uniform background (e.g., they must be either both dark or both similarly lit). According to this theory, only under matching intertrial-interval and retention-interval conditions will the sample be judged appropriately against its background. When the conditions during the intertrial interval and retention interval are different, the pigeons may not be able to judge the duration of the sample against a consistent background, and, because of the novelty of the retention interval, matching accuracy will drop to chance levels at relatively short retention intervals. Spetch and Rusak called this modification of the subjective shortening hypothesis the relative duration hypothesis.

Although results consistent with the relative duration hypothesis have been reported (e.g., Grant \& Spetch, 1991, 1993; Roberts, Macuda, \& Brodbeck, 1995; Spetch, Grant, \& Kelly, 1996; Spetch \& Rusak, 1992; Spetch \& Wilkie, 1982, 1983; Wilkie \& Willson, 1990), an alternative ex- 
planation of these effects, the ambiguity hypothesis, has recently been proposed (Sherburne, Zentall, \& Kaiser, 1998). According to the ambiguity hypothesis, if the intertrial-interval and retention-interval conditions match on test trials, the pigeons may not readily discriminate between them. If the pigeons treat the novel retention interval as an intertrial interval, then when comparisons appear at the end of the retention interval, it would be as if no sample had been presented. Because no sample is more similar to a short sample than to a long sample, the pigeons should tend to choose the comparison that would have been correct after a short sample, and that tendency should increase with longer retention intervals (longer retention intervals are even more like intertrial intervals).

To distinguish between the relative duration hypothesis and the ambiguity hypothesis, Sherburne et al. (1998) trained pigeons on an event-duration conditional discrimination, with one group of pigeons exposed to dark intertrial intervals (as is typical) and the other group exposed to intertrial intervals that were illuminated by a houselight. Both groups of pigeons were then tested, over trials, with dark and lit intertrial intervals and dark and lit retention intervals (parametrically manipulated). On the one hand, according to the relative duration hypothesis, the choose-short effect should occur whenever, on any given trial, the intertrial interval and the retention interval match. Therefore, the choose-short effect would be expected to occur on all test trials in which the intertrial interval and the retention interval were either both dark or both lit (presumably, independently of the lighting conditions during the intertrial interval during training). On the other hand, according to the ambiguity hypothesis, the choose-short effect should occur whenever the retention-interval illumination was similar to the intertrialinterval illumination that was used during training. Therefore, the choose-short effect would be expected to occur for the group trained with a lit intertrial interval, on all test trials in which the retention interval was lit, and for the group trained with a dark intertrial interval, on all test trials in which the retention interval was dark (independently of the lighting conditions during the intertrial interval on that test trial). Consistent with the ambiguity hypothesis, the choose-short effect occurred only under conditions of ambiguity (i.e., when the retentioninterval conditions matched the intertrial-interval conditions from training).

Furthermore, if the ambiguity hypothesis is correct, when ambiguity is reduced by differentiating the retention interval from the intertrial interval, overall matching accuracy would be expected to improve. Consistent with this prediction, Sherburne et al. (1998) found significantly better matching accuracy when the training intertrial interval was differentiated from retention interval. If the absence of a choose-short effect with differentiated intertrial interval and retention interval was produced by the novelty of the retention interval, as Spetch and Rusak (1992) suggest, then the opposite should have been found (i.e., the pigeons should have performed worse when the intertrial interval and the retention interval were different).

The results of Sherburne et al. (1998) suggest that the choose-short effect may result from the perceptual similarity between the intertrial intervals in training and the retention intervals in test. But even when this source of ambiguity is reduced by making the events distinctive from each other, the introduction of novel retention intervals may result in a reduction in matching accuracy not based on memory loss.

Even if pigeons are trained with a single retention interval and then tested with longer and shorter retention intervals, the novelty of the retention-interval durations on test trials-the failure of the comparison stimuli to appear when expected on test trials with longer retention intervals or their appearance sooner than expected on test trials with shorter retention intervals - could disrupt matching accuracy. Thus, one should not assume that giving pigeons experience with a particular retention interval would eliminate the ambiguity (or generalization decrement) produced by introducing novel retention intervals.

To address the problem of retention-interval novelty, Spetch and Rusak (1992, Experiment $2 b$ ) trained pigeons with short (2-sec) and long (8-sec) samples of food with variable delays $(2,4,6$, and $8 \mathrm{sec})$ and compared matching performance on short- and long-sample trials for this group with a group trained with a fixed $(5-\mathrm{sec})$ delay. Three aspects of the results of this experiment are noteworthy. First, if a delay following the offset of a sample results in the subjective shortening of the sample, training with variable retention intervals should make acquisition of this task very difficult. Presumably, the subjective memory for the long sample after a delay of $8 \mathrm{sec}$ should appear quite similar to the subjective memory for the short sample after a delay of $2 \mathrm{sec}$. Yet, acquisition of this task was no more difficult for the pigeons that acquired the task with variable retention intervals than for the pigeons that acquired the task with a fixed retention interval. Clearly, a subjective shortening model (Spetch \& Wilkie, 1982) or a trace strength model (Staddon \& Higa, 1999) is inadequate to account for acquisition with variable delays.

Second, although some evidence for a choose-short bias was found at the longer retention intervals, the magnitude of that effect was relatively small (at the 8-sec retention interval, the pigeons' choice of the comparison associated with the short sample was only $6.9 \%$ greater than their choice of the comparison associated with the long sample), relative to the typical choose-short effect (about $25 \%$ at a 10 -sec retention interval, as estimated from Spetch \& Rusak, 1992, Figure 3.6). Finally, unlike typical retention functions that decline rapidly with increasing retention intervals (see, e.g., the drop of about $37 \%$ correct from 0 - to $10-\mathrm{sec}$ retention intervals presented by Spetch \& Rusak, 1992, Figure 3.6), the drop in matching accuracy from short (2-sec) retention intervals 
to long (8-sec) retention intervals was a very modest $7.8 \%$ correct. Thus, when trained with retention intervals of variable duration, there was very little forgetting of these duration samples.

The present experiments were designed to provide pigeons with unambiguous experience with retention intervals from the start of training to reduce the potential disruption in matching accuracy produced by novel retention intervals. At the same time, the distinguishing characteristics of the intertrial intervals, relative to the retention intervals, were manipulated between groups to ensure that there would be no confusion between the intertrial intervals and the retention intervals.

\section{EXPERIMENT 1}

In Experiment 1, pigeons were trained on an eventduration matching task with 2- and $10-\mathrm{sec}$ samples, and, from the start of training, the pigeons experienced variable retention intervals of $0,1,2$, and 4 sec. Retention functions could then be assessed under conditions in which delays were not novel. Under these conditions, there should be less ambiguity about the "meaning" of the retention interval, and the retention functions should better reflect the pigeons' memory for sample duration.

Pigeons in Group Dark-Dark were trained with dark intertrial intervals and dark retention intervals, whereas pigeons in Group Light-Dark were trained with lit intertrial intervals and dark retention intervals. If the chooseshort effect results from ambiguity between similar intertrial intervals and retention intervals, as the results of Sherburne et al.'s (1998) experiment suggest, then Group Light-Dark should acquire the task more quickly and should perform better with increasing retention intervals than should Group Dark-Dark. Better performance with increasing retention intervals would be predicted because, even though subjects should learn that intertrial intervals follow comparisons and retention intervals follow samples and that should reduce the ambiguity, for Group LightDark the differential ambient-light conditions during the intertrial interval and the retention interval should further differentiate the two events. Although the relative duration hypothesis does not make a specific prediction about differences between the two groups in acquisition or in overall performance, the confusion that is hypothesized to occur when the intertrial interval and the retention interval do not match (e.g., for Group Light-Dark) would lead one to predict that Group Dark-Dark should acquire the task faster and perform at higher levels of accuracy with increasing retention intervals. Following acquisition with 0- to 4-sec retention intervals, additional testing was conducted with novel, extended retention intervals (first $0-8 \mathrm{sec}$ and then $0-16 \mathrm{sec}$ ).

\section{Method}

\section{Subjects}

Twelve White Carneaux pigeons (retired breeders, males and females) obtained from the Palmetto Pigeon Plant (Sumter, SC) served as subjects. They were maintained in individual cages at $80 \%$ of their free-feed weights in a room with a $12: 12$-h light:dark cycle. All pigeons had had previous experience with simple simultaneous discriminations involving hue stimuli.

\section{Apparatus}

The operant chamber contained a pigeon compartment measuring $37 \mathrm{~cm}$ high, $34 \mathrm{~cm}$ across the response panel, and $30 \mathrm{~cm}$ from the response panel to the back wall. Three circular pecking keys ( $2.5 \mathrm{~cm}$ in diameter) were located on the response panel. The edges of the pecking keys were $5.7 \mathrm{~cm}$ apart, with their bottom edges $23 \mathrm{~cm}$ above the wire mesh floor.

Located behind each pecking key was a 12-stimulus, in-line projector with $28-\mathrm{V}, 0.1-\mathrm{A}$ lamps that projected a white light on the center key and red $(R)$ and green $(G)$ hues on the left and right keys. The red and green hues were produced by Kodak Wratten Filters Nos. 26 and 60 , respectively.

A rear-mounted grain feeder provided reinforcement and was located midway between the bottom of the pecking keys and the floor. A 28-V, 0.1-A houselight provided general chamber illumination and was located $5.0 \mathrm{~cm}$ above the center response key. The test chamber was connected to a computer in an adjacent room. An exhaust fan mounted on the outside of the chamber and white noise delivered through a speaker mounted on the response panel provided sound masking.

\section{Procedure}

Training. The pigeons were randomly assigned to one of two groups. For one group, the houselight was illuminated during the intertrial interval (Group Light-Dark), whereas for the other group, the intertrial interval was dark (Group Dark-Dark). Each trial began with the illumination of the center key for either 2 or $10 \mathrm{sec}$. Immediately following the termination of the center key stimulus, a dark retention interval of $0,1,2$, or $4 \mathrm{sec}$ occurred, followed by the $R$ and $G$ comparison stimuli on the left and right response keys. Correct choices were followed by 2 -sec access to mixed grain and the 10-sec intertrial interval, whereas incorrect choices were followed by the intertrial interval alone. For half of the pigeons in each group, $\mathrm{R}$ was correct following the 2 -sec sample and $\mathrm{G}$ was correct following the 10 -sec sample, whereas for the remaining pigeons, those conditions were reversed. The $\mathrm{R}$ and $\mathrm{G}$ comparisons occurred equally often on the left and right response keys.

Each training session consisted of 96 trials, 48 of each sample type. Each retention interval occurred equally often ( 24 trials each). The trials were arranged in blocks of 16 , such that each trial type was represented once during a block ( 2 sample types $\times 4$ retention intervals $\times 2$ comparison arrangements). Two trial sequences were used. The trials in each sequence were randomly ordered with the following restrictions: no sample type occurred for more than 4 consecutive trials, and no comparison occurred on the same side for more than 4 consecutive trials. Pigeons were trained until they achieved a criterion of $75 \%$ correct on each of the two sample types at the 0 -sec retention interval for 10 sessions. This criterion was used to avoid the possibility of either floor or ceiling effects, which might possibly obscure an asymmetry in the retention functions. These sessions were often, but not always, successive. The data from those 10 sessions were used to assess the retention functions for the familiar (training) retention intervals. Pecks to each of the sample types were also recorded.

Testing. The day after completion of training, the pigeons were tested with successively longer retention intervals. The second delay set consisted of $0-, 2-, 4-$, and $8-\mathrm{sec}$ retention intervals, and the third delay set consisted of $0-, 4-, 8-$, and $16-\mathrm{sec}$ retention intervals. The pigeons remained on each of Delay Sets 2 and 3 for 15 sessions unless their performance at the longest retention interval exceeded $80 \%$ correct for two consecutive sessions. In this case, the pigeons were advanced to the next delay set. This criterion was im- 
posed to avoid the possibility of a ceiling effect that might have resulted in artifactually produced, nondivergent retention functions. Four pigeons reached this criterion during Delay Set 2 and were moved to Delay Set 3 sooner than the other pigeons.

\section{Results and Discussion}

The pigeons in Group Light-Dark completed the 10 criterion sessions of training significantly faster $(M=$ 28.8 sessions, $S D=8.2$ ) than those in Group Dark-Dark $(M=59.5$ sessions, $S D=32.1)[t(10)=2.27]$. In all analyses, the $p<.05$ level of significance was used.

A three-way mixed-factor analysis of variance (ANOVA), with group (Light-Dark vs. Dark-Dark), sample type (short vs. long), and retention interval $(0,1$, 2 , and $4 \mathrm{sec}$ ) as factors, conducted on the 10 criterion sessions of training indicated that Group Light-Dark performed better overall than did Group Dark-Dark $[F(1,10)=7.29]$. Faster acquisition during training and better overall performance by Group Light-Dark than by Group Dark-Dark supports the ambiguity hypothesis because, for Group Light-Dark, the retention intervals should not be confused with the intertrial intervals, whereas for Group Dark-Dark, they might be confused. According to the relative duration hypothesis, however, Group Light-Dark should have had more difficulty learning the task because these pigeons should not have been able to accurately judge the sample durations against the inconsistent lit-intertrial-interval/dark-retention-interval background.

Sample pecking was averaged over the 10 criterion sessions of training. As expected, the pigeons pecked more often when the samples were $10 \mathrm{sec}(2.90 \mathrm{pecks} /$ trial $)$ than when the samples were $2 \sec (0.32$ pecks/trial $)$. However, even when corrected for opportunity, the pigeons still pecked at the long sample at a higher rate $(0.29$ pecks $/ \mathrm{sec})$ than at the short sample $(0.16 \mathrm{pecks} / \mathrm{sec})$. It is not clear whether this difference was due to the uninformative nature of the first $2 \mathrm{sec}$ of each sample or to the fact that the pigeons may not always have been near the response key when it was turned on.

Not as expected was the finding that the pigeons in Group Dark-Dark pecked at the samples significantly more (3.02 pecks/trial and $0.40 \mathrm{pecks} / \mathrm{sec})$ than did the pigeons in Group Light-Dark $(0.18$ pecks/trial and $0.04 \mathrm{pecks} / \mathrm{sec}$ ). A two-way mixed-factor ANOVA performed on the sample pecking data, with group and sample type as factors, indicated that there was a significant effect of group $[F(1,118)=15.55]$ (the pigeons pecked the sample key more when the houselight was lit during the intertrial interval) and a significant effect of sample type $[F(1,118)=15.99]$ (the pigeons pecked the 10 -sec sample more than the 2 -sec sample). There was also a significant group $\times$ sample type interaction $[F(1,118)=$ 14.01] (the pigeons pecked the 10 -sec sample substantially more, 5.52 pecks/trial, when the intertrial interval was dark than when it was lit).

A similar analysis performed on the rate of sample pecking data (pecks $/ \mathrm{sec})$ indicated similar effects of group
$[F(1,118)=17.47]$, sample type $[F(1,118)=6.52]$, and group $\times$ sample type interaction $[F(1,118)=9.14]$. Thus, the pigeons pecked at a higher rate when the sample light appeared in a dark chamber, and their rate of pecking increased after the first $2 \mathrm{sec}$ of sample presentation.

\section{Retention Functions}

Retention during training for each group is presented in Figure 1. On criterion sessions during training, Group Dark-Dark did not appear to show a clear choose-short effect, although matching accuracy on the short-sample trials appeared to be somewhat better than on the longsample trials. Similarly, Group Light-Dark showed no choose-short effect. In fact, Group Light-Dark appeared to show better matching accuracy on the long-duration trials than on the short-duration trials at the 4-sec retention interval. Analyses were performed on the criterionsession training data for each group using the error term from the group $\times$ sample type $\times$ retention interval interaction.

Group Dark-Dark. On criterion sessions during training, Group Dark-Dark showed somewhat better performance on the short-sample trials than on the longsample trials $[F(1,30)=13.25]$ and a reliable effect of retention interval $[F(3,30)=19.00]$ but did not show a significant sample type $\times$ retention interval interaction $[F(3,30)=1.89]$. The lack of the significant interaction and the relatively high performance on the long-sample trials at all retention intervals indicate that the typical choose-short effect was not found. This result is consistent with the ambiguity hypothesis because, presumably by training with retention intervals, the pigeons would not encounter them as novel events on test trials and, thus, they should not easily confuse them with the intertrial intervals.

Similar effects were found for Delay Sets 2 and 3, but, with the longer delay sets, there was no significant effect of sample type $[F \mathrm{~s}(1,30)=1.45$ and 2.71 , respectively], and again there was no significant sample type $\times$ retention interval interaction (both $F \mathrm{~s}<1$ ). Thus, when the pigeons were trained with retention intervals that varied between 0 and $4 \mathrm{sec}$, not only did a choose-short effect fail to emerge but, even when the retention intervals were extended to as long as $16 \mathrm{sec}$, no significant interaction was found. These results are inconsistent with the subjective shortening account of the choose-short effect. Furthermore, they suggest that when pigeons are trained with variable delays, short samples and long samples are forgotten at about the same rate.

Group Light-Dark. During training, Group LightDark did not perform better overall on one sample type than on the other $[F(1,30)=2.21]$. Although the retention functions were almost flat, there was a small but significant effect of retention interval $[F(3,30)=4.98]$. There was also a significant sample type $\times$ retention interval interaction $[F(3,30)=13.21]$. The source of that interaction was a significant difference between match- 
Group Dark-Dark
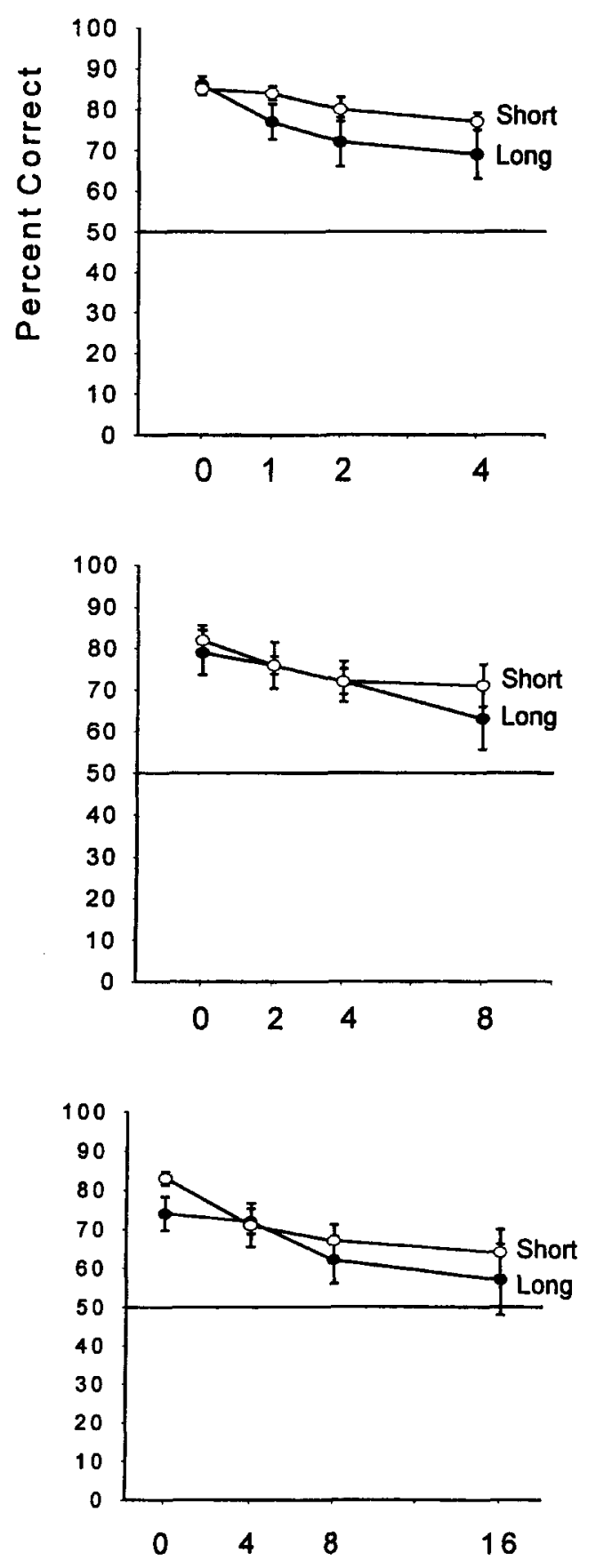

Group Light-Dark
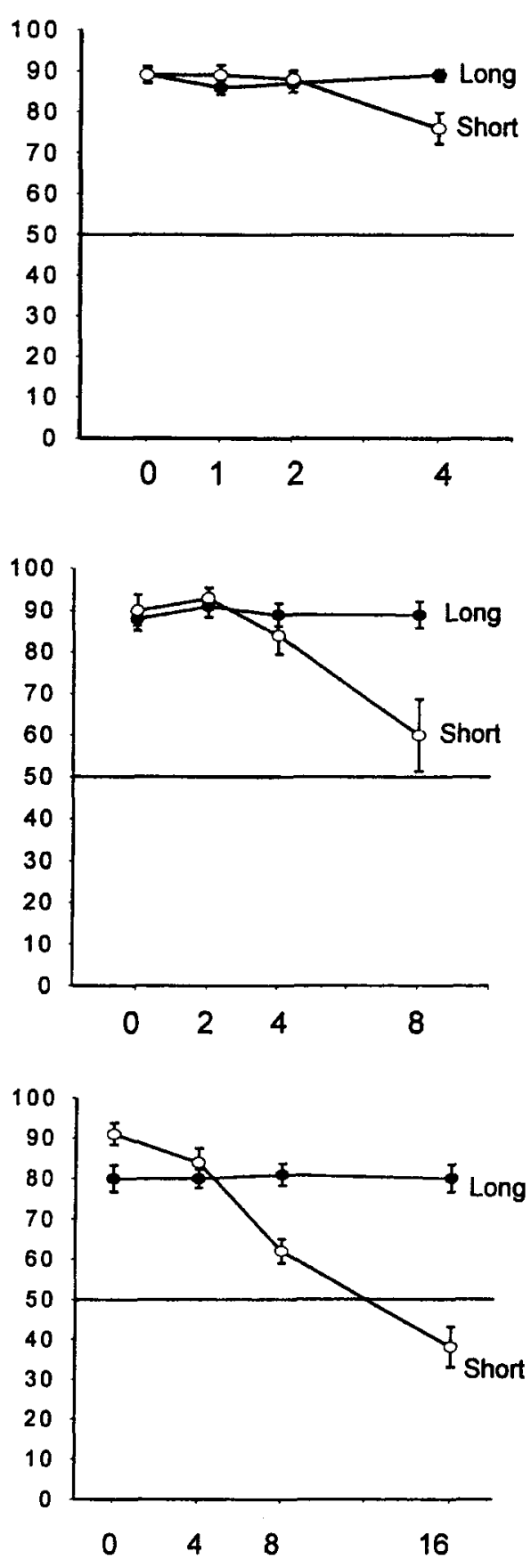

Retention Interval (s)

Figure 1. Experiment 1: Retention functions for short- and long-sample trials for Delay Sets 1, 2, and 3.

ing accuracy on long- and short-sample trials at the 4-sec retention interval $[F(1,30)=16.74]$, whereas matching accuracy at $0-, 1-$, and $2-\mathrm{sec}$ retention intervals was virtually identical on long- and short-sample trials.

For Delay Set 2, Group Light-Dark showed significantly better performance, overall, on the long-sample trials than on the short-sample trials $[F(1,30)=9.71]$ and a significant sample type $\times$ retention interval interaction, similar to the one shown for Delay Set 1.

The effects found for Delay Set 3 were similar to those found on for Delay Set 2. By the third delay set, performance on the short-sample trials actually fell below 


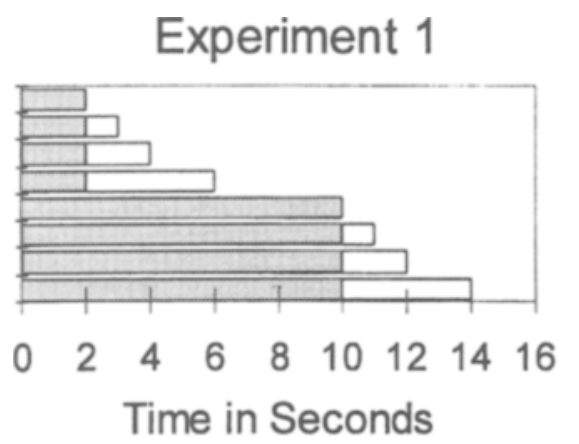

Experiment 2

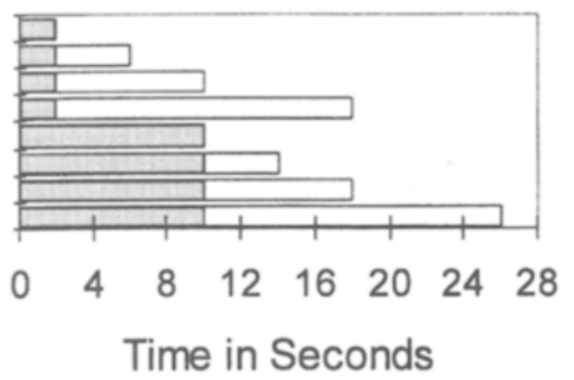

Figure 2. Schematic of the duration of the samples and the retention intervals (RIs) during training with each of the trial types in Experiments 1 and 2.

chance, indicating that, at longer retention intervals, the pigeons had developed a bias to choose the comparison associated with the long sample. In other words, when a short sample was followed by a relatively long retention interval, the pigeons tended to respond as though they had been presented with a long sample. These results suggest that the pigeons in this group were not just timing the duration of the sample but were also including the duration of the retention interval. That is, they were timing from the onset of the sample to the onset of the comparisons. This "strategy" may have begun in training, when such timing would have resulted in high matching accuracy, indistinguishable from timing the samples alone. Using this strategy, performance could have been high on both sample types because, as illustrated in Figure 2 , the short sample together with the longest (4-sec) training retention interval was still shorter than the long sample together with the shortest $(0-\mathrm{sec})$ training retention interval.

But why should such a strategy develop in Group Light-Dark when the only difference between the two groups was the presence or absence of a houselight during the intertrial interval? One possibility may be that, although the pigeons in Group Dark-Dark should use the onset of the sample to start timing, the pigeons in Group Light-Dark could use either the onset of the sample or the offset of the houselight to start timing. Because the more salient of the two events may be the offset of the houselight, that is likely to be the event that the pigeons used to start timing. If the pigeons used the offset of the houselight to start timing, rather than the onset of the sample, perhaps the offset of the sample was not as salient an event as it would have been had they used the sample onset to start timing and, thus, perhaps the pigeons in Group Light-Dark used the onset of the comparisons as a cue to stop timing. In contrast, because the pigeons in Group Dark-Dark used the onset of the sample to start timing, they were apparently encouraged to use the offset of the sample to stop timing.

The hypothesis that Group Dark-Dark used the onset of the sample to start timing whereas Group Light-Dark used the offset of houselight to start timing is supported by the sample-pecking data described earlier. Recall that the pigeons in Group Dark-Dark pecked the samples significantly more than did the pigeons in Group LightDark. Choose-long effects of the kind found here have been reported in both rats (Santi, Weise, \& Kuiper, 1995) and pigeons (Santi, Stanford, \& Coyle, 1998) when samples involved durations of tone, but, to our knowledge, this is the first time such a bias has been reported in pigeons using visual sample durations.

The purpose of including Group Light-Dark in Experiment 1 was to further reduce potential ambiguity by clearly distinguishing the intertrial intervals from the retention intervals. Unexpectedly, the way the two events were distinguished appears to have encouraged the pigeons to time through the retention intervals used in training. In Experiment 2, we attempted to distinguish between the intertrial intervals and the retention intervals and, at the same time, discourage the pigeons from timing through the retention intervals by lengthening the training retention intervals.

\section{EXPERIMENT 2}

The results of Experiment 1 suggest that when the intertrial interval is lit, pigeons may begin timing at the offset of the houselight and continue to time until comparisons appear. The purpose of Experiment 2 was to discourage pigeons from timing through the retention intervals by using retention intervals in training that were longer than the training retention intervals used in Experiment 1 . With samples of 2 and $10 \mathrm{sec}$ and training retention intervals of $0,4,8$, and $16 \mathrm{sec}$, the total time from the onset of the sample to the onset of the comparisons provides an ambiguous cue for comparison choice for five of the eight trial types (2-sec samples and 8-sec retention intervals, 2 -sec samples and 16-sec retention intervals, 10-sec samples and 0-sec retention intervals, 10 sec samples and 4-sec retention intervals, and 10-sec samples and 8 -sec retention intervals). This ambiguity is depicted in graphical form in Figure 2.

In Experiment 2, we also tested the hypothesis that the relative lack of salience of the sample offset did not sufficiently encourage the pigeons to stop timing. Perhaps if the retention interval onset was made more salient than 


\begin{tabular}{lcccc}
\multicolumn{7}{c}{$\begin{array}{c}\text { Table 1 } \\
\text { The Events That Occurred During a Trial } \\
\text { for Each Subgroup of Experiment } 2\end{array}$} & \\
\hline Group & ITI & Sample & RI & Comparisons \\
\hline Light-Light-Dark & W HL & 2- and 10-sec W KL & Dark & R and G KL \\
Light-Dark-Light & W HL & 2- and 10-sec Dark & B HL & R and G KL \\
Light-Light-Light & W HL & 2- and 10-sec W KL & B HL & R and G KL \\
\hline
\end{tabular}

Note-W, white; HL, houselight; KL, keylight; B, blue; R, red; G, green; ITI, intertrial interval; RI, retention interval.

the offset of the response key, the pigeons would be more likely to stop timing at the start of the retention interval. Thus, the pigeons in Experiment 2 were divided into three subgroups. To evaluate the effects of the increase in training retention interval alone, one of the subgroups, Group Light-Light-Dark, had lit intertrial intervals, lit response-key samples, and dark retention intervals (similar to Group Light-Dark from Experiment 1). For the two remaining subgroups, the intertrial intervals were illuminated by a white houselight, and the retention intervals were made more distinctive by illuminating them with a blue houselight (in a location different from the white houselight). For Group Light-Light-Light, the samples were durations of a white keylight, as they were in Experiment 1, whereas for Group Light-Dark-Light, the samples were durations of darkness (no key light). Dark durations were used as samples for one subgroup because it was thought that it might make the start and the end of the samples most distinctive. Furthermore, because pigeons typically peck at a lit sample but not at a dark sample, the results of this subgroup would allow us to evaluate the contribution of sample-key pecking to the memory of those samples.

\section{Method}

\section{Subjects}

Six White Carneaux pigeons similar to those used in Experiment 1 were used.

\section{Apparatus \\ The operant chamber and stimuli were the same as those used in Experiment 1 . In addition, a second houselight located at the cen- ter of the ceiling of the chamber was covered with a Roscolene Fil- ter No. 863, which illuminated the chamber with a blue light when the lamp was lit.}

\section{Procedure}

As in Experiment 1, sample durations were 2 and $10 \mathrm{sec}$, and comparisons were $R$ and $G$. The pigeons were trained from the first session with variable retention intervals of $0,4,8$, and $16 \mathrm{sec}$. For all pigeons, the intertrial intervals and retention intervals were distinct from each other. The pigeons were assigned to one of three conditions. Group Light-Light-Dark was trained with lit intertrial intervals and dark retention intervals, conditions that were the same as for Group Light-Dark in Experiment 1. The remaining two groups were trained with intertrial intervals and retention intervals that were both lit. The intertrial interval and retention interval were made distinct by the illumination of the white houselight during the intertrial interval and the illumination of the blue houselight during the retention interval. For Group Light-Light-Light, a white keylight defined the duration samples, as it did in Experiment 1, whereas for Group Light-Dark-Light, a period of darkness defined the duration samples. A criterion session was defined as a session in which a pigeon was at least $75 \%$ correct on both 2 - and $10-\mathrm{sec}$ sample trials at the 0 -sec retention interval (as it was in Experiment 1). The pigeons were trained until they achieved a criterion of $75 \%$ correct on each of the two sample types at the 0 -sec retention interval for 40 sessions. This larger number of training sessions was used because we assumed that the extended retention intervals would make the task relatively difficult. The design of Experiment 2 is presented in Table 1.

\section{Results and Discussion}

The mean number of sessions to complete training for the three subgroups was $88.6(S E=3.8)$ sessions [Group Light-Light-Dark, 89.2 ( $S E=8.8)$; Group Light-DarkLight, $89.2(S E=7.5)$; Group Light-Light-Light, 87.2 $(S E=4.9)]$. The rate of acquisition among the three subgroups did not differ significantly $(F<1)$.

For all groups, the retention functions were relatively parallel, suggesting that retention of the long and short samples did not differ. A three-way mixed-factor ANOVA, with group, sample type, and retention interval as factors, revealed only a significant effect of retention interval $[F(3,27)=59.9]$. Overall retention performance as a function of sample type is presented in Figure 3. The data from each subgroup were analyzed separately using the error term from the group $\times$ sample type $\times$ retention interval interaction. Whereas all three subgroups showed a significant effect of retention interval, none of them showed a significant difference in performance on the long-and short-sample trials or a significant sample type $X$ retention interval interaction (all $F \mathbf{s}<2.1$ ).

It is possible that the groups might have shown asymmetries earlier in training, and these asymmetries may have gone away by the end of the 40 sessions. Therefore, we conducted analyses on the first 10 criterion sessions during training. Similar to the original analysis, there was a significant effect of retention interval $[F(3,27)=$ 43.6], but no other effect was significant (all $F \mathrm{~s}<1.3$ ).

For all subgroups in Experiment 2, as retention intervals increased, performance on both long- and short-duration samples trials decreased at similar rates. In other words, none of the groups showed evidence either of a chooseshort effect or of a choose-long effect. Apparently, the relatively long retention intervals used in training, rather than the presentation of the blue houselight during the retention interval, resulted in the absence of a choose-long effect. Furthermore, that performance did not differ significantly between Groups Light-Light-Light and Light- 


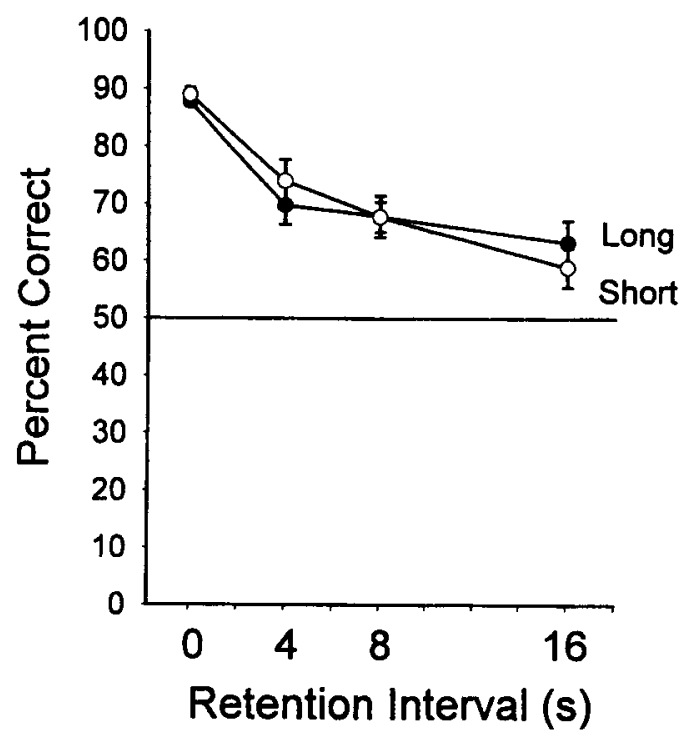

Figure 3. Experiment 2: Retention functions for short- and long-sample trials for the pigeons trained with retention intervals of $0,4,8$, and 16 sec. For all pigeons the intertrial intervals were lit, and the ambient light conditions were distinctively different from the intertrial interval.

Dark-Light suggests that the opportunity to peck is relatively unimportant in the retention of duration samples.

Again, analysis of the sample-pecking data indicated that the pigeons pecked the long sample significantly more $(3.07 \mathrm{pecks} / \mathrm{trial})$ and at a faster rate $(0.31 \mathrm{pecks} / \mathrm{sec})$ than they pecked at the short sample $(0.27$ pecks/trial and 0.15 pecks/sec) $[F \mathrm{~s}(1,117)=35.86$ and 12.24 , respectively]. However, neither total sample pecking nor the rate of sample pecking differed significantly among the groups (both $F \mathrm{~s}<1$ ).

\section{GENERAL DISCUSSION}

The results of Experiment 1 suggest that training with retention intervals essentially eliminated the choose-short effect that normally occurs when intertrial-interval and retention-interval conditions are similar (at least at the retention intervals used in training). This finding suggests that when pigeons are given the opportunity to discriminate between similar intertrial intervals and retention intervals, the ambiguity between these events is virtually eliminated. Furthermore, in Experiment 1, increasing the range of retention intervals to $8 \mathrm{sec}$ and then to $16 \mathrm{sec}$, failed to produce a significant choose-short effect.

Similar results were found for Group Light-Dark at the training retention intervals; however, for this group, a small but significant choose-long effect was found, and that effect increased in magnitude as the range of retention intervals increased to $8 \mathrm{sec}$ and then to $16 \mathrm{sec}$. The choose-long effect suggests that when the intertrial interval was illuminated, the pigeons did not stop timing until the comparisons appeared.
The results of this experiment cannot readily be accounted for by the relative duration hypothesis. According to the relative duration hypothesis, Group Light-Dark should not have been able to time the sample duration accurately because the temporal background (intertrial interval and retention interval) of the sample did not match. However, in Experiment 1, Group Light-Dark learned the task more quickly and performed better overall than did Group Dark-Dark. Furthermore, the relative duration hypothesis cannot readily explain why Group Light-Dark showed a choose-long effect and Group Dark-Dark did not show a typical choose-short effect.

Experiment 2 was conducted to further disambiguate the intertrial intervals from the retention intervals, as well as to encourage the pigeons to time only the sample durations (i.e., to stop timing when the retention interval began). This was accomplished by training with retention intervals as long as $16 \mathrm{sec}$. The retention functions for all three subgroups were virtually parallel, suggesting that these training conditions were successful in removing both choose-short and choose-long biases. The implication of the results of Experiment 2 is that when the retention intervals are distinctively different from the intertrial intervals and the pigeons are discouraged from timing through the retention intervals by training them with long retention intervals, it can be shown that memory for duration samples does not subjectively shorten with time, as has been assumed (e.g., Grant \& Spetch, 1991, 1993; Spetch \& Rusak, 1992; Staddon \& Higa, 1999). In this regard, it is of interest that Santi et al. (1995) reported parallel retention functions (similar to those found in Experiment 2 of the present study) for rats trained with visual duration samples. Although it is difficult to make meaningful cross-species comparisons, Santi et al.'s (1995) finding indicates that parallel retention functions following duration sample-matching training are not unique to the present experiments.

The relative duration hypothesis is based on the analogical coding hypothesis, a unidimensional trace-strength model predicated on the idea that the strength of a trace is proportional to the sample presentation time and is inversely proportional to the time since the offset of the sample (Staddon \& Higa, 1999). A graphical presentation of the model appears in Figure 4. For purpose of illustration, it was assumed that, at the time of sample offset (0-sec delay), the trace of the short sample was about half the strength of the long sample and that the strength of the memory traces decreased at a rate of about $20 \%$ per sec. Although the values presented in Figure 4 are hypothetical and somewhat arbitrary, they are consistent with the data reported by Sherburne et al. (1998) collected under typical conditions. According to this model, choice of the comparison stimulus at any delay depends on the strength of the short and long samples experienced during training, relative to the traces of those samples at the time of test. During training with 0 -sec retention intervals, a strong trace results in a "long" response and a moderate trace results in a "short" response. With the introduction 


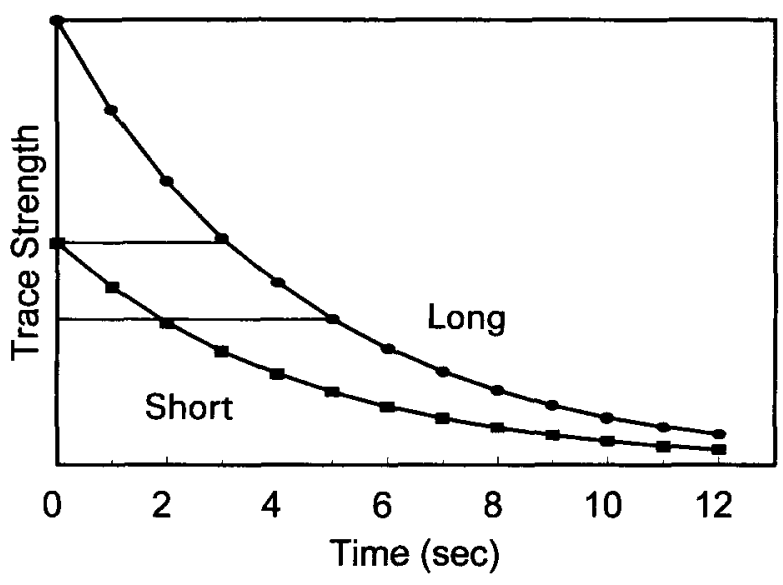

Figure 4. Theoretical functions based on Staddon and Higa's (1999) trace-strength model of memory for durations. The relative functions were selected to approximate choice accuracy data reported by Sherburne et al. (1998) in which pigeons trained with short (2-sec) and long (10-sec) samples at a 0 -sec delay showed a bias to choose the "short" comparison when the sample was long and the delay was 2 sec. It was assumed that, at the time of sample offset (0-sec delay), the trace of the short sample was about half the strength of the long sample and that the strength of the memory traces decreased at a rate of about $20 \%$ per second.

of retention intervals, however, both traces weaken, and what was a strong $(10-\mathrm{sec})$ trace with a 0 -sec retention interval becomes a moderate trace with longer retention intervals. According to this theory, as the retention intervals increase, long samples are treated as short because the strength of a long sample at longer retention intervals resembles the strength of a short sample at a 0 -sec retention interval. But how does such a trace-strength model account for data from the present experiment and those of Spetch and Rusak (1992) in which acquisition involved variable retention intervals. Sherburne et al. (1998) reported that matching accuracy on long-sample trials fell below chance ( $50 \%$ correct) at retention intervals of 2 $4 \mathrm{sec}$. The fact that pigeons can readily learn to match at the same time sample durations with retention intervals as short as $0 \mathrm{sec}$ and as long as $16 \mathrm{sec}$ suggests that trace strength (Spetch \& Rusak, 1992; Staddon \& Higa, 1999) alone cannot be an effective cue for comparison choice. This point is readily apparent in Figure 4 . There it can be seen that the trace strength of a 2-sec sample at its offset is similar to the trace strength of a 10-sec sample at a 3sec delay. Similarly, the trace strength of a 2-sec sample at a 2-sec delay is similar to the trace strength of a $10-\mathrm{sec}$ sample at a 5-sec delay.

Alternatively, training with variable retention intervals may be a special case for which the trace-strength model may not apply. According to this view, when durationsample matching is acquired with no delays or with a fixed delay, trace strength may control comparison choice, but under conditions such as those used in the present experiments, which may discourage such coding, duration samples may be coded by the duration of the sample or perhaps even categorically (as long vs. short). For example, Grant and Kelly (1998) found no choose-short effect when pigeons were trained with variable delays of 1 $30 \mathrm{sec}$ using short and long samples of keylight (Experiment 1), and they found a small choose-short effect under similar conditions but with short and long samples of houselight (Experiment 2). They concluded that categorical coding occurs when analogical or strength codes are ineffective (i.e., when there is overlap between the strengths of a short sample with little delay and a long sample with a long delay). Although it is possible that pigeons use different coding processes in remembering the duration of samples, depending on whether a strength model would work, it would be more parsimonious to posit that memory for the duration of the sample is the rule and that what appears to be choice based on trace strength is an artifact of retention interval novelty.

Given that pigeons do not code duration samples by two different processes, how do they code them? One possibility is that pigeons may represent the duration samples categorically at their offset (i.e., as "short" and "long"; Kraemer, Mazmanian, \& Roberts, 1985), and they may forget those representations at comparable rates. Alternatively, pigeons may represent the samples prospectively as response intentions (e.g., to peck the red comparison if the sample was short or to peck the green comparison if the sample was long). Although presently, there is little evidence that samples are coded as prospective response intentions in two-alternative matching tasks (Zentall, 1998), the parallel retention functions found in the present research do not allow one to rule out such "strategic" learning.

Recently, it has been suggested that pigeons may use differential behavior directed to the samples as the basis for choice of the comparison stimuli (Weaver, Dorrance, $\&$ Zentall, 1999). When samples are defined as the presence versus the absence of an event (e.g, a yellow keylight vs. a dark key), it is the occurrence of pecking (the yellow stimulus) and the absence of pecking (the dark key) that appears to determine comparison choice (Zentall, Kaiser, Clement, Weaver, \& Campbell, 2000). Although presence-/absence-sample matching involves a somewhat different procedure from duration-sample matching, the similarity in divergence of retention functions found with the two procedures (relatively steep retention functions falling below chance with long and presence samples, and relatively high and flat retention functions with short and absence samples) leads one to suspect that these procedures may involve similar underlying mechanisms (Dougherty \& Wixted, 1996; Gaitan \& Wixted, 2000). Consistent with this hypothesis, in the present experiments, there was significantly more pecking in the presence of the long samples than in the presence of the short samples. Furthermore, the rate of sample pecking was greater on long-sample trials than on short-sample trials. Thus, differential sample pecking may also play a role in the acquisition of duration-sample matching. 
The results of the present experiments suggest, more generally, that when animals are presented with novel test conditions, biased choice may result. Thus, it is quite likely that typical tests of animal memory using novel retention intervals may not accurately reflect the underlying memory process (Weaver et al., 1999; Zentall, 1998; Zentall et al., 2000).

\section{REFERENCES}

DougherTY, D. H., \& WIXTED, J. T. (1996). Detecting a nonevent: Delayed presence-vs.-absence discrimination in pigeons. Journal of the Experimental Analysis of Behavior, 65, 81-92.

GaITAN, S. C., \& WIXTED, J. T. (2000). The role of "nothing" in memory for event duration in pigeons. Animal Learning \& Behavior, 28, 147-161.

Grant, D. S., \& Kelly, R. (1998). The effect of variable-delay training on coding of event duration in pigeons. Learning \& Motivation, 29, 49-67.

Grant, D. S., \& SPETCh, M. L. (1991). Pigeons' memory for event duration: Differences between choice and successive matching tasks. Learning \& Motivation, 22, 180-190.

Grant, D. S., \& Spetch, M. L. (1993). Analogical and nonanalogical coding of samples differing in duration in a choice-matching task in pigeons. Journal of Experimental Psychology: Animal Behavior Processes, 17, 186-193.

Kraemer, P. J., Mazmanian, D. S., \& Roberts, W. A. (1985). The choose-short effect in pigeon memory for stimulus duration: Subjective shortening versus coding models. Animal Learning \& Behavior, $13,349-354$

Roberts, W. A., Macuda, T., \& Brodbeck, D. R. (1995). Memory for number of light flashes in the pigeons. Animal Learning \& Behavior, 23, 182-188.

Santi, A., Stanford, L., \& Coyle, J. (1998). Pigeons' memory for event duration: Differences between visual and auditory signals. $A n-$ imal Learning \& Behavior, 26, 163-171.

SANTI, A., Weise. L., \& Kuiper, D. (1995). Memory for event duration in rats. Learning \& Motivation, 26, 83-100.
Sherburne, L. M., Zentall, T. R., \& Kaiser, D. H. (1998). Timing in pigeons: The choose-short effect may result from pigeons' "confusion" between delay and intertrial intervals. Psychonomic Bulletin \& Review, 5, 516-522.

Spetch, M. L., Grant, D. S., \& Kelly, R. (1996). Procedural determinants of coding processes in pigeons' memory for duration. Learning \& Motivation, 27, 179-199.

SPeTCH, M. L., \& Rusak, B. (1992). Time present and time past. In W. K. Honig \& J. G. Fetterman (Eds.), Cognitive aspects of stimulus control (pp. 47-67). Hillsdale, NJ: Eribaum.

SPetch, M. L., \& Wilkie, D. M. (1982). A systematic bias in pigeons' memory for food and light durations. Behavior Analysis Letters, 2, 267-274.

SPETCH, M. L., \& Wilkie, D. M. (1983). Subjective shortening: A model of pigeons' memory for event duration. Journal of Experimental Psychology: Animal Behavior Processes, 9, 14-30.

STAdDon, J. E. R., \& Higa, J. J. (1999). Time and memory: Towards a pace-maker free theory of interval timing. Journal of the Experimental Analysis of Behavior, 71, 215-251.

Weaver, J. E., Dorrance, B. R., \& Zentall, T. R. (1999). Present/absent sample matching in pigeons: Is comparison choice controlled by the sample stimulus or by differential sample responding? Animal Learning \& Behavior, 27, 288-294.

WILKIE, D. M., \& WILLSON, R. J. (1990). Discriminable distance analysis supports the hypothesis that pigeons retrospectively encode event duration. Animal Learning \& Behavior, 18, 124-132.

ZENTALL, T. R. (1998). Symbolic representation in animals: Emergent stimulus relations in conditional discrimination learning. Animal Learning \& Behavior, 26, 363-377.

Zentall, T. R., Kaiser, D. H., Clement, T. S., Weaver, J. E., \& CampBELL, G. (2000). Presence/absence-sample matching by pigeons: Divergent retention functions may result from the similarity of behavior during the absence sample and the retention interval. Journal of Experimental Psychology: Animal Behavior Processes, 26, 294304.

(Manuscript received March 23, 2000; revision accepted for publication July 20,2000 .) 